\title{
Los ojos en coulisse o Kant entre bastidores: la deshumanización de Ortega vista por Václav Černý
}

\section{The Eyes in the Wings, or, Kant Offstage: Ortega's Dehumanization as seen by Václav Černý}

José Luis Bellón Aguilera [116683@mail.muni.cz] Masarykova univerzita, República Checa

\section{RESUMEN:}

Este artículo trata de La deshumanización del arte (1925) del filósofo español José Ortega y Gasset, centrándose en la lectura que de la misma hace el hispanista y filósofo checo Václav Černý en un trabajo de 1929. El artículo se concentra en La deshumanización, no en todos los escritos anteriores y posteriores, sobre arte y literatura, del filósofo madrileño, por ser el que es analizado en la obra citada de V. Černý. El hispanista y filósofo checo mantiene que el manifiesto teórico de Ortega sobre el arte y las literaturas de vanguardia y sus tesis sobre las mismas, aparentemente rupturistas, se anclan en la teoría estética de Kant, y por tanto comparten elementos con la teoría estética del romanticismo alemán, objetivo fundamental del ataque, junto al realismo, del filósofo madrileño. El análisis de V. Černý es interesante para, primero, reconstruir la tesis de una ideología literaria compartida en el campo literario y, segundo, la de un inconsciente ideológico común que la estructuraría. El trabajo finaliza señalando otras cuestiones que suscita el excelente análisis de V. Černý.

\section{PAlabras Clave:}

Deshumanización; Ortega; V. Černý; estética kantiana

\section{Abstract:}

This article deals with Spanish philosopher Ortega's The Dehumanization of Art (1925), but focusing in how Czech hispanist and philosopher V. Černý read it in a work published in 1929. The article discusses just The Dehumanization of Art, not the other essays on art and literature of Ortega, because these are not read by V. Černý. According to the latter, Ortega's theoretical manifesto, apparently groundbreaking, is in fact rooted in Kantian aesthetics, sharing many elements with Romanticism and Realism, the main targets of Ortega's attack. V. Černý analysis is interesting, firstly, to reconstruct the idea of a literary ideology shared in the literary field, and, secondly, that of the existence of a common ideological unconscious structuring it. Our article ends pointing out other questions incited by the analysis of V. Černý.

\section{KEYWORDS:}

Dehumanization; Ortega; V. Černý; Kantian aesthetics 


\section{Introducción}

El título de este artículo está tomado de la parte de La deshumanización del arte titulada "Unas gotas de fenomenología”. La expresión "en coulisse” significa “entre bastidores” y ya se explicará por qué la usamos. Antes es importante aclarar que no nos interesa reconstruir un hipotético pensamiento general de las ideas de Ortega sobre el arte y la literatura, sino La deshumanización... en el momento concreto de su elaboración, su recepción en el contexto checo y los aciertos de esta. Por ello no hemos usado la edición de Paulino Garagorri en la editorial Alianza, de 1991, sino las Obras completas (tomo III) (1966). Primero, resumiremos sucintamente los planteamientos centrales de la obra de Ortega que analizamos, para que destaque más la lectura de V. Černý, que expondremos a continuación. Finalizaremos con las cuestiones provocadas por la misma.

Sobre Ortega y Gasset no es necesario hacer una introducción, pero quizás sí lo será - para el lector español - decir algo sobre el hispanista y filósofo Václav Černý (1905-1987), o al menos situarlo. Creo que gran parte de su obra no está traducida al español (la de su contemporáneo Jan Mukařovský (1891-1975), sí, por Jarmila Jandová y Emil Volek en Plaza y Janés, 2000). El trabajo sobre Ortega, titulado «Ortegy y Gassetova teorie „umění odlidštěného“» (orig. 1929), lo hemos leído en una recopilación de ensayos sobre literatura española, Studie o španělské literatuře, aparecido en 2008.

\section{Primera parte. Filosofía, teoría literaria, política}

\subsection{Madrid era una fiesta}

Antes de entrar en La deshumanización del arte, y dado que es una obra muy conocida y estudiada, vale la pena recalcar el ambiente de efervescencia cultural en el que apareció, en 1925. Para estas notas de contextualización nos hemos servido, de entre los muchos textos posibles, de Nieto Yusta (2007: 285-286).

En 1925 se celebró en el Palacio del Retiro de Madrid la Primera Exposición de la Sociedad de los Artistas Ibéricos. Participaron artistas como Rafael Barradas, Alberto Sánchez, Salvador Dalí, Ángel Ferrant, José Gutiérrez Solana, Benjamín Palencia o Ucelay, entre otros. La muestra se acompañó de la publicación de un catálogo y de una serie de conferencias en las que participó Ortega (de las cuales queda "El arte en presente y en pretérito"). Fue un año decisivo para el arte en España y de todo ello saldría la Sociedad de Artistas Ibéricos en 1931, muy importante a nivel nacional e internacional. En 1925, un año después de la aparición del Primer Manifiesto surrealista de André Breton, reciben el Premio Nacional de Literatura Rafael Alberti con Marinero en tierra y Gerardo Diego y sus Versos humanos; Manuel de Falla compone Concierto para clavicémbalo, se estrena en Sevilla su Retablo y Guillermo de Torre publica Literaturas europeas de vanguardia, la biblia (según Alejo Carpentier) para conocer la vanguardia europea en España. El mismo año se inaugura en París la Exposición Internacional de Artes Decorativas, de gran influjo para los arquitectos y artistas españoles; se publica El realismo mágico de Franz Roh. 
Se trata, por tanto, un campo cultural en plena transformación, en proceso de relevo generacional y de una asombrosa, apabullante creatividad, en calidad y cantidad. Los agentes inmersos en esa electrizante atmósfera saben que ocupan el centro de atención intelectual y cultural y pugnan por mantenerse en el vértice de la pirámide de productividad artística, literaria, filosófica. El polo de la vanguardia del campo cultural se ha constituido en dominante muy rápido - en apenas unos años - ocupando el lugar hegemónico y desbancando al realismo, el naturalismo y el romanticismo tardío (sus decadentismos, intimismos, sentimentalismos) aún palpitante en el Modernismo, que fue vanguardia en su momento pero que había sido rechazado, por agotamiento, en el turno de siglo. Los representantes principales de las corrientes mencionadas pertenecen a generaciones más provectas, si no han muerto ya. Es importante no olvidar que el público general consumía más literatura realista y naturalista. La alta tensión de la energía emocional de las vanguardias explica la ironía y agresividad del texto de Ortega, apuntalada por su tajante seguridad teórica y la implicación en su proyecto ideológico-político para España: modernización, liberalismo, élite dirigente. ${ }^{1}$

\subsection{Una obra rupturista, para la inmensa minoría}

La deshumanización del arte es una obra llena de matices, pero los argumentos centrales de su robusta argumentación son claros. Se presenta casi como un manifiesto, exaltando el arte, la música y la literatura de vanguardia, al tiempo que lo teoriza como una ruptura radical con la estética anterior. Ha surgido un canon estético radicalmente nuevo - proclama - que rompe con la estética propiamente burguesa, ya entonces extendida a toda la sociedad, y que era básicamente romántica y realista.

La obra se inicia con un ataque a una forma de sociología del arte: dedicarse a los efectos sociales de este, dice Ortega, es como «tomar el rábano por las hojas», expresión denigratoria del gusto popular en las que abunda toda la obra (como la de la borrachera, véase abajo). El filósofo madrileño parte de tres ideas: que la sociología del arte no se ha hecho, que el arte nuevo es impopular y que está en relación con la música. La evidente alusión a la revolución teatral lopesca (el "arte nuevo") es una metáfora aplicada al propio contexto; y sobre la música se establece el paralelo con la impopularidad, por incomprendida, de la música contemporánea. Se exaltan las vanguardias, en fin, como arte minoritario.

Frente a la popularidad del romanticismo, el nuevo arte es impopular; sin embargo, por "impopular" debe entenderse, señala Ortega, "anti-popular", esto es, que no está hecho para ser comprendido por el público en general. Teniendo en cuenta este fracaso de público, se comprende su éxito entre las minorías intelectuales, las únicas capacitadas para comprenderlo. Nuestro filósofo madrileño manifiesta un etnocentrismo de clase obvio:

Se acerca el tiempo en que la sociedad, desde la política al arte, volverá a organizarse, según es debido, en dos órdenes o rangos: el de los hombres egregios y el de los hombres vulgares. Todo el

1 Cabría traer al paso La rebelión de las masas (desde 1929 en el diario El Sol), y la labor de importación, difusión y transmisión de ideas punteras de la Revista de Occidente (fundada en 1923). 
malestar de Europa vendrá a desembocar y curarse en esa nueva y salvadora escisión. La unidad indiferenciada, caótica, informe, sin arquitectura anatómica, sin disciplina regente en que se ha vivido por espacio de cincuenta años, no puede continuar. Bajo toda la vida contemporánea late una injusticia profunda e irritante: el falso supuesto de la igualdad real entre los hombres. Cada paso que damos entre ellos nos muestra tan evidentemente lo contrario que cada paso es un tropezón doloroso.

Si la cuestión se plantea en política, las pasiones suscitadas son tales que acaso no es aún buena hora para hacerse entender. Afortunadamente, la solidaridad del espíritu histórico a que antes aludía permite subrayar con toda claridad, serenamente, en el arte germinal de nuestra época los mismos síntomas y anuncios de reforma moral que en la política se presentan oscurecidos por las bajas pasiones. (Ortega 1966: 356)

Si la argumentación fuera objetiva, es decir, si se sostuviera que hace falta un capital educacional o cultural para comprender la vanguardia intelectual y artística, sería más acertado, pero las raíces de este racismo de clase se encuentran en el proyecto político orteguiano para España que mencionamos al inicio de este artículo (la construcción de una moderna élite intelectual y política). El lenguaje usado, se trate de burros o de caballos de raza, no es amable: "La masa cocea y no entiende. Intentemos nosotros hacer lo inverso" (356), si bien hay que conceder al texto una capacidad para el matiz, en la misma página: no es que los que entienden el nuevo arte valgan más, sino que "evidentemente son distintos". A pesar de todo, no es una cuestión de gusto bárbaro o culto, sino de óptica.

\subsection{Una cuestión de óptica}

La cuestión no es el gusto subjetivo, particular, sino adónde se dirige la mirada. Como buen kantiano, a su pesar, de gustibus non est disputandum: lo que pasa es que la mayoría, la masa, no sólo no entiende la obra joven, el arte nuevo, sino que le humilla no comprenderlo y ello le disgusta.

En primer lugar, explica Ortega, el arte joven es un "arte artístico": es antirromántico y antirrealista porque separa rotundamente la vida y el arte. Las personas que no entienden que una cosa es el arte y otra la vida no cambian de actitud cuando contemplan no sólo el arte nuevo, sino cualquier forma de arte: se dejan llevar, se emborrachan, van a "revolcarse apasionadamente en la realidad humana que en la obra está aludida" (p. 358), confunden la vida y el arte y pierden las dos. Miran sin ver.

El primer símil óptico usado por Ortega es el de un jardín contemplado desde una ventana. ${ }^{2}$ Ver aquel a través de la ventana implica que no nos fijamos en ella $y$, para verla, necesitamos focalizar los ojos de forma que el jardín deviene un conjunto de borrones. Pero entre la realidad

2 Símil de la ventana bastante común, por otro lado, en las propedéuticas artísticas de base psicologista y subjetivista. Cf. Henry James (1843-1916), en el prefacio crítico a la novela de 1880, The Portrait of a Lady: "The house of fiction has in short not one window, but a million - a number of possible windows not to be reckoned, rather; [...] They are but windows at the best, mere holes in a dead wall, disconnected, perched aloft" (The Art of the novel, New York \& London: Charles Scribner's Sons, 1962, pág. 46). 
y yo hay un marco y un cristal, una pantalla que si se toca se siente. Si no se ve, sucede como cuando se lee una novela realista y uno se deja engañar por la ficción, creyendo que es la realidad. El arte se esfuma. Hay que centrarse en el medio sin olvidar la realidad, distanciarse de la obra y de la realidad representada en ella de forma que se aprenda la realidad de su artificio. Paradójicamente, hay que deshumanizar la mirada si se quiere comprender su humanidad.

La estética de vanguardia es antirrealista y antirromántica, básicamente porque, para el filósofo madrileño, el arte actual "romántico-naturalista" se ha agotado y lo sustituye una nueva sensibilidad, que tiende, "1. ${ }^{\circ}$, a la deshumanización del arte; $2 .^{\circ}$, a evitar las formas vivas; $3 .^{\circ}$, a hacer que la obra de arte no sea sino obra de arte; $4 .^{\circ}$, a considerar el arte como juego, y nada más; $5 .^{\circ}$, a una esencial ironía; $6 .^{\circ}$, a eludir toda falsedad, y, por tanto, a una escrupulosa realización. En fin, 7. ${ }^{\circ}$, el arte, según los artistas jóvenes, es una cosa sin trascendencia alguna” (Ortega 1966: 360). Ortega tratará uno por uno estos puntos, pero antes de ello, hace un paréntesis fenomenológico, una suspensión del análisis para explayarse sobre la importancia de la mirada, con otro símil óptico: el de la habitación con el muerto en el apartado "Unas gotas de fenomenología”, de donde hemos tomado el título de este artículo.

En una habitación un hombre agoniza; junto al moribundo, se hallan presentes cuatro personas: su mujer, un médico, un reportero y un pintor. Les acompañan sus puntos de vista. Las formas de vivir y de ver la escena se gradúan en escalas de distanciamiento: la mujer está destrozada, no tiene distancia, no contempla la escena sino que la vive. El médico implica un grado de separación algo mayor, pero debido a su interés profesional, no se separa del todo; el periodista, otro profesional, no siente, debe escribir para su periódico un relato como "pura escena", pero pensado para conmover. El reportero es, obviamente, horaciano a pesar de sí mismo (no por nada incluye Ortega una cita de Horacio). "Dócil a Horacio [...] no "vive" la escena, "finge" vivirla” (362). (Como se sabe, del verbio fingir se deriva etimológicamente el sustantivo ficción.) La última persona de cuerpo presente en el cuarto del agonizante es el pintor:

Por último, el pintor, indiferente, no hace otra cosa que poner los ojos en coulisse. Le trae sin cuidado cuanto pasa allí; está, como suele decirse, a cien mil leguas del suceso. Su actitud es puramente contemplativa, y aun cabe decir que no lo contempla en su integridad; el doloroso sentido interno del hecho queda fuera de su percepción. Sólo atiende a lo exterior, a las luces y las sombras, a los valores cromáticos. En el pintor hemos llegado al máximum de distancia y al mínimum de intervención sentimental. (Ortega 1966: 362)

Como se dijo al inicio, la expresión "en coulisse" significa "entre bastidores". El pintor mira la realidad y se distancia radicalmente de ella. La actitud es de un distanciamiento frío, radical, y de ahí la aparente "deshumanización". La falta de sentimientos y frialdad irónica del pintor es la del nuevo arte, pero sólo hasta cierto punto (sobre todo esto volveremos más abajo).

Tras el paréntesis sobre la mirada deshumanizada, la obra analiza los puntos expuestos antes. Resumiremos al máximo puesto que no podemos comentarlos uno por uno y, además, se trata de comentar la lectura del filósofo e hispanista checo V. Černý.

La nueva sensibilidad estética extirpa el aspecto de realidad vivida: como en Ramón Gómez de la Serna (al que Ortega coloca al lado de Proust y Joyce), se dirige a los «barrios bajos de la atención», a los detalles de la vida cotidiana, y posee voluntad de estilo. Ortega subraya la 
anormalidad del realismo en la historia del arte, la monstruosidad de un anti-estilo artístico incapaz de distinguir entre arte y la vida. El realismo, como el romanticismo, no es un estilo, sino un carácter: todas las épocas han tenido un estilo cuyos rasgos se fugaban de la representación mimética, hasta el bizquear del realismo.

Este bizqueo o mirada doble lo explica el filósofo madrileño en estos términos: pensamos en ideas, ideas de objetos, no pensamos la realidad, por tanto el arte nuevo acierta al estilizar la realidad, al deshumanizarla (los términos estilización y deshumanización son equivalentes), al desrealizar la realidad. El nuevo arte hace vivir las ideas en su irrealidad, realiza lo real en cuanto irreal. Esto lo relaciona Ortega con una teoría de la metáfora, la cual es definida como un instinto para huir de la realidad, demasiado terrible para enfrentarse a ella cara a cara.

Por otro lado, el filósofo insiste en el carácter lúdico, de ironía, de juego, del nuevo arte. El humor es fundamental: el arte nuevo no se toma en serio a sí mismo, sabe de su intrascendencia: la trascendencia profética de los artistas anteriores se opone a la conciencia nueva de la caducidad y el relativismo: incluso el arte mismo se hace broma, porque es un arte que desvela su estructura y mecánica, el ser artificio técnico, su álgebra de metáforas. Se ríe de la grandilocuencia y los grandes temas románticos, rehúye la narración que revuela en torno a las idas y venidas de personas. ${ }^{3}$

Humor, juego, deporte. El arte de vanguardia es un arte joven, el de una generación que se opone a la vieja (Ortega entonces tenía 42 años). El conflicto de generaciones y de tradiciones es una tendencia interna a la dinámica del arte, enfrentándose en el momento incluso a sí mismo: hoy es el culto al cuerpo frente al envejecido culto al espíritu, los ritmos de la historia son viriles y juveniles: «El cariz que en todos los órdenes va tomando la existencia europea anuncia un tiempo de varonía y juventud. La mujer y el viejo tienen que ceder durante un período el gobierno de la vida a los muchachos, y no es extraño que el mundo parezca ir perdiendo formalidad» (Ortega 1966: 384).

Vitalidad, lozanía, virilidad, fuerza. A pesar de todo, del carácter manifiestamente combativo y provocativo del ensayo, su párrafo final revela un aristotélico deseo por el justo medio; si el arte nuevo "quiere crear de la nada", "Yo espero", escribe Ortega, "que más adelante se contente con menos y acierte más".

\subsection{Un primer balance}

Vamos a detenernos un momento para recapitular. Ortega elogia la metáfora, el metateatro de Pirandello, a Debussy; sus análisis y argumentación reúnen sintéticamente varias tradiciones filosóficas: fenomenología, racionalismo, vitalismo y biologicismo. De sobra es conocida la influencia del psicologismo y el neokantismo en su obra. Pero, por otra parte, a cualquier crítico literario, términos como "deshumanización" o "desrealización", le evocan, obviamente, primero, el de "distanciamiento", enraizado, como se sabe, en la noción del formalismo ruso del mecanismo de "hacer extraño" (priyom otstraneniya), la defamiliarización de Viktor Shklovsky,

3 La tralla contra los profetas y la insistencia en el humor, probablemente evoque la figura de Unamuno. Como si Ortega se situara así frente al filósofo del sentimiento trágico de la vida y de los grandes conflictos existenciales. 
u ostranenie; segundo, el efecto de distanciamiento del teatro, o extrañamiento (alemán Verfremdungseffekt), en checo zcizovací efekt, quizás también odcizení (aunque este signifique más bien “alienación”). En la atmósfera europea de las vanguardias la circulación internacional de teorías e ideas debía hacer familiares estos términos, este lenguaje. Sobre las fuentes alemanas de estos pasajes y de algunas ideas de arte, véase Orringer (1979).

Por otro lado, hay algo latente y es la del "arte por el arte". ¿Es Ortega formalista? En un momento de La deshumanización... se plantea tímidamente la posibilidad de estar entrando en la discusión del "arte puro" (la cuestión de la "poesía pura”, recuérdese a Juan Ramón Jiménez), pero no continúa el hilo de los planteamientos, quizás porque intuye hacia donde conducen. Navega entre la Escila y Caribdis de un arte mundano pero autónomo, no comprometido. ${ }^{4}$

\section{Puntos sobre íes: Ostranenie - deshumanización}

Podría plantearse que el paralelo entre Shklovski y Ortega es precipitado. Para el primero, la "literariedad" es un uso des-cotidianizado del lenguaje que "despierta" al lector del automatismo. Él da ejemplos del romanticismo y del realismo (Tolstoi), todo lo cual no cuadraría con el “antirromanticismo" de Ortega y su "deshumanización" vanguardista, tecnicista. Sin embargo, la cuestión aquí no son las etiquetas epocales, historicistas, de la periodización académica tradicional, que tiende a ser lineal y a ver periodos o corrientes que se abren y cierran reproduciendo estadios en evolución de unas formas o ideas que expresan universales.

Tanto Shklovski como Ortega hablan de una "experiencia" artística que sucede cuando se distingue entre vida y arte - se haga o no "adrede", digamos para entendernos. En términos de Shklovski esto podría traducirse como la oposición binaria "lenguaje cotidiano" (vida) / "lenguaje literario" (arte) (luego Jakobson hablará de su "función poética"). Lo que planteamos es que el sustrato ideológico compartido está teorizado, tiene forma teórica, - como se explicará a continuación - en Kant: el esfuerzo del formalismo ruso, la creación del concepto de "literariedad" es una revisión que separa ética y estética y hace de las formas en un "a priori” universalista. (Lo que ni Ortega ni Shklovski ven es que el lenguaje, sea literario o no, está preñado de ideología inconsciente, de una creencia en ese mito del lenguaje literario, artístico, poético: incluso si es el lenguaje de un "campo literario" específico.) ${ }^{5}$

En suma, José Ortega y Gasset no es un importador de las teorías del formalismo ruso, pero comparte algo del lenguaje, lo conociera o no. Lo que planteamos, en definitiva, es la co-existencia de un humus ideológico común: la creencia en unas formas puras, autónomas, desideologizadas o deshistorizadas, pero sin "arte por el arte". Pese al conflicto con las estéticas anteriores, hay algo común en el romanticismo y el realismo. El enfrentamiento con ellos es superficial, no es un conflicto de cánones (terminología que tomamos de Norbert Elias y Arnold Hauser) en busca una revolución simbólica, sino de inversión de un paradigma estético. La lectura de Václav Černý aclarará lo que planteamos.

4 Es imposible no pensar en la propuesta de Pierre Bourdieu, en el epílogo de Las reglas del arte (1992), sobre una creación autónoma pero mundana ("Pour un corporatisme de l'universel”, en Bourdieu 1992, 459-472).

5 Cf. el artículo de Blanco Aguinaga, "Sobre Estilística y Formalismo ruso" (1997). Pero un estudio riguroso de toda esta problemática se encuentra en La norma literaria (1984, 1994, 2001), y en el reciente Para una teoría de la literatura (2015), de Juan Carlos Rodríguez. 


\section{Segunda parte: Kant en coulisse}

\subsection{Un hispanista procedente del campo filosófico}

«Ortegy y Gassetova teorie „umění odlidštěného“» aparece en 1929. Al final del volumen antológico de trabajos de hispanística de Václav Černý que lo recoge (2008), hay una nota biográfica breve elaborada por el también célebre hispanista Josef Forbelský (nacido en 1930), centrada en su vida y consagración institucionales. La hemos utilizado para elaborar un muy breve diagrama de su situación en el campo universitario checo, en el subcampo de la literatura comparada y románica (véase apéndice).

Su preparación filosófica, fundamentalmente en la corriente bergsoniana, y el contexto intelectual, germanizado pero en transición e hibridación ideológica, se asemeja al de Ortega. Černý poseía competencias de sobra para una crítica filosófica del material orteguiano. Como se ve en el diagrama, el campo intelectual en el que está situado era muy rico, de una gran concentración de talento y, posteriormente, tras la emigración y la guerra, de impacto global ${ }^{6}$. De entre sus obras citamos algunas contemporáneas de la época: Ideové kořeny současného umění, 1929 (PhDr. 1928: Bergson a ideologie současného romantismu), Karel Čapek, 1936 y Esej o básnickém baroku, 1937.7 Ignoramos la respuesta de Ortega o si hubo siquiera eco, pero su lectura es un análisis impecable de las raíces kantianas de La deshumanización del arte. Veámosla.

\subsection{Ortega cabeza abajo.}

Los planteanteamientos del hispanista checo sobre La deshumanización del arte son, básicamente, tres: primero, que Ortega lo que ha invocado es la autonomía artística como fundamento creativo; segundo, que esa creencia en la autonomía pone de manifiesto una base filosófica kantiana; por último (tercero), que el filósofo de Madrid, a pesar de su declarado antirromanticismo y antirrealismo, comparte con estas corrientes más de lo que cree, incluyendo, entre otros aires de familia, la exaltación de la ironía como modus operandi. V. Černý se centra, sobre todo, en desmontar el supuesto antirromanticismo.

6 Hay un trabajo que hacer sobre las relaciones entre el círculo lingüístico de Praga y la crítica literaria checa de las literaturas románicas. Sobre el impacto global, no hay que sobrestimar pero tampoco subestimar: El estructuralismo de Praga existe desde alrededor de finales de los años 20: Vilém Mathesius, Nikolái Trubetskói, Roman Jakobson, Jan Mukařovský, René Wellek, etc. Wellek emigraría a USA, y con Austin Warren (1899-1986), publicaría la famosa Theory of Literature en 1948 (otras dos edic., 1956 y 1962); la traducción española en la editorial Gredos (1953²) fue prologada a petición de Wellek por Dámaso Alonso, de la estilística, conectada a la escuela checa a través de Raimundo Lida. Las raíces provienen del formalismo ruso: Roman Jakobson se había trasladado a Praga 1920 (como miembro de una misión diplomática soviética para continuar sus estudios doctorales), y aunque enseñaba en la universidad de Brno, influyó en el Círculo Lingüístico de Praga. Nunca se insistirá demasiado en la importancia de la crítica checa y rusa en el desarrollo de la historia y crítica literaria occidentales. En una nota de 1990 a su novela Žert (1967) Kundera describía la crítica literaria checa de la segunda mitad de los años sesenta - los herederos - en términos quizás demasiado inflados, pero no demasiado injustos: "Pro literární kritiku v Čechách druhé půle šedesátých let (tehdy neměla česká literární kritika sobě rovnou snad nikde na světě, jak jsem si později v cizině uvědomoval) [...]“.

$7 \quad$ No nos ha sido posible reconstruir las redes intelectuales de procedencia de V. Černý, ni los discípulos directos. 
Tras el resumen de la obra analizada y sin aludir directamente a la desfamiliarización formalista, la "desautomatización" de V. Shklovski o la "función poética" de R. Jakobson, V. Černý plantea (rechazando de plano una idea de Taube ${ }^{8}$ ) que la afirmación básica de Ortega es la de la autonomía de la obra artística:

Podle mého názoru se hrubě mýlí [Taube]. Základní afirmací Ortegovou je koneckonců, že dílo umělecké je realitou autonomní, mimo sféru zájmů vitálních, extrareální, žijící svým specifickým, stylizovaným životem nad objektivní skutečností. Kdo tu bude váhat poznati starou, správnou koncepci apriorní estetiky kantovské, pro niž krásu nelze hledat už uskutečněnou, mimo subjekt (jak to dělala krasověda antická), mezi realitami pomyslnými (Platónovy Ideje) nebo smyslovými (Aristoteles), poněvadž závisí od duchové konstituce právě subjektu, a dle níž tvoření umělcovo je činností vylučující veškeren smysle vnější (tendenčnost etickou aj., zájmovost vitální), mající svůj účel v sobě samé. (Černý 2008: 276)

Como se lee en la Crítica del juicio estético kantiana - añade el hispanista y filósofo checo - y como afirma Ortega, “...čili dílo probouzí dojem krásy, pokud je dílem stylizovaným, disrealizovaným” (op. cit. 276). No hay resistencia a "la ideología kantiana” (lit. "kantovské ideologii”).

Černý localiza, además, ecos de Nietzsche, y de Simmel. Y sobre la ironía, la paradoja de que fue el romántico Schlegel el que la invocó casi como programa: la ironía como categoría estética ("renovada", cf. también Nieto, 2007: 292); y concluye: "Me atrevo a afirmar que somos la sexta generación de románticos" (Černý, 2007: 277), “veo diferencias, pero también cuánta vecindad”. En definitiva, todos los artistas - dirá al final del texto - andan tras los “andrajos de la eternidad” (lit. „za těmi cáry věčnosti“, p. 280).

\section{3. ¿Quién tiene la razón?}

El trabajo de Václav Černý es una denegación directa de la supuesta originalidad radical de Ortega y, aunque estamos de acuerdo, hay que matizar, puesto que su propuesta ofrecida no es menos parcial, si bien en su caso se trata de Bergson y la intuición, de los impulsos del subconsciente y de una especie de irracionalismo visionario que equipara a la propuesta del pensador de Madrid. Aquí el teórico checo quizás va demasiado lejos, pero no tanto si se piensa en la herencia nietzscheana en Ortega y en su raciovitalismo. Para ambos, hay razones del corazón que la razón no entiende (Blaise Pascal).

Václav Černý muestra el envés ideológico de la deshumanización artística, los elementos compartidos con aquellos a los que desacredita. Se trata, dice, de una ideología artística (literaria) que a pesar de las apariencias comparte más de lo que niega. En definitiva, que la matriz ideológica es la misma (nosotros usamos la terminología del filósofo e hispanista granadino Juan Carlos Rodríguez (1990)). Nuestro teórico checo explica La deshumanización del arte como

8 Otto von Taube, de manera algo reductiva, plantea que en el texto de Ortega hay resistencia a las ideas europeas y un regreso al “alma española”. Desconocemos a quién se refiere V. Černý. Quizás al polígrafo, filósofo y jurista alemán Otto Adolf Alexander Freiherr von Taube (1879-1973), algunos de cuyos escritos fueron prohibidos durante el nazismo y que optó por el exilio interior. 
si se tratase de una inversión que coloca las formas por encima de aquello que las sostiene (el pathos, los sentimientos, la luz interior del sujeto), para volver a lo mismo: la búsqueda del mundo de los sueños, los andrajos de eternidad de la naturaleza humana.

Pero hay que precisar: ¿En qué sentido es kantiano (o neokantiano) el texto de Ortega? La mejor forma de explicar el análisis de V. Černý es servirse de la obra de un colaborador y amigo de Ortega, Manuel García Morente (1886-1942), de su libro La filosofía de Kant, una introducción a la filosofía, aparecido en 1917. ${ }^{9}$ Él mismo tradujo al español la Crítica del juicio en 1914. En esa obra (de 1790 y de fuerte influencia en el romanticismo alemán, como se sabe) Kant se ocupa del juicio estético, tras dedicarse a la moral y el deber en la segunda de sus obras, la Crítica de la razón práctica (1788).

Para Kant, según explica García Morente, lo que define el juicio estético es la falta de interés: lo bello es lo que gusta por sí mismo; el auténtico juicio estético es un juicio desinteresado, puro, si se quiere "un interés desinteresado" (García Morente, 1975: 179). La contemplación de lo bello no puede depender sino de sí misma: "La esfera, pues, del arte y de la belleza no debe confundirse ni con el conocimiento (lógica) ni con la moral. Constituye por sí misma una provincia autónoma de la cultura humana. Ni el arte es, como la ciencia, enseñanza, ni, como la moral, indicación de un ideal de vida colectiva" (íd., p. 180). De esta manera se separa lo bello y lo bueno, la ética de la estética; el juicio estético no aporta conocimento del objeto contemplado, es un puro a priori. Lo bello no se refiere a un fin determinado, sino que es un fin formal, independiente de su representación. El gusto es subjetivo, cierto, pero en cuestiones de arte hay algo espiritual, no existe solo la mera sensualidad animal, sino algo universal, una idea de lo bello que trasciende lo subjetivo: "Podríamos, con expresión algo paradójica, pero exacta, decir que el juicio estético posee una objetividad subjetiva” (íd., p. 183).

Hay algunos problemas en todo esto que señalaremos en las conclusiones, pero es inevitable no acordarse del deshumanizado pintor y de la "desrealización” orteguiana, la separación entre vida y arte, atravesada de vitalismo. No significa que haya una coincidencia punto por punto, pero hay demasiados elementos claves o básicos como para pasarlos por alto. La cimentación es la misma, aunque Ortega haya suplantado - invertido - las formas "puras" con formas "impuras", es decir, "intrascendentes", cotidianas, alegres, vitales. Como su "raciovitalismo", un intento de sintetizar el vitalismo y el racionalismo, un intento de encontrar una salida de emergencia al atolladero filosófico de lo irracional. Sin embargo, en la obra de Ortega hay algo más que una expresión más de la ideología literaria de la modernidad surgida con el romanticismo y sus impasses.

\subsection{Los andrajos de eternidad se aprenden a coser en la escuela}

El problema fundamental es cómo se aprende lo bello. Si se lee el texto con atención, se encuentran los impasses a los que aludíamos en el apartado anterior. ¿Cómo ver la universalidad a-moral, eterna, de los objetos bellos?

9 Manuel García Morente es autor de las Lecciones preliminares de filosofía (de 1938; escritas a partir de un curso en Argentina en la univ. Tucumán, en su exilio de 1937), importantes en la formación filosófica de los estudiantes universitarios españoles. Fue un divulgador inteligente de la filosofía de Kant en España. 
Los juicios estéticos, si bien no son universales, como los juicios de conocimiento, encierran, sin embargo, una aspiración a la universalidad. Si yo digo: esta estatua es de mármol, la universalidad de mi juicio es total. Mas si digo: esta estatua es bella, la universalidad de mi juicio, aunque no es total, aspira, sin embargo, a serlo. Sé que puede haber quien la declare fea; pero ese tal me aparece como persona de mal gusto, de escasa formación artística. Es lo mismo en el fondo que cuando, ante la expresión de una verdad cierta, oigo que alguien no la admite; ese alguien me parecerá o un tonto o un ignorante, que por defecto de conocimiento no puede comprender aquella verdad. Pero la verdad misma la creo verdad, aunque sólo pocas mentes la piensen, porque creo que es verdad por sí misma. De igual suerte una belleza, aunque fundada tan sólo en mi emoción subjetiva, se me aparece como una verdad, que si no es admitida por todos, es simplemente porque no pueden ellos ascender a sentirla.

Hay, pues, en el juicio estético, aunque basado exclusivamente en el sentimiento personal, un cierto grado de universalidad y de necesidad, es decir, de objetividad. Podríamos, con expresión algo paradójica, pero exacta, decir que el juicio estético posee una objetividad subjetiva. (García Morente 1975: 183) [Subrayados nuestros]

¿Y quién enseña o aprende a "sentir" en su interior los pasmantes ecos de "lo universal"? Quizás por ello desarrolla Kant la idea de lo sublime y la de los sujetos creadores especiales (los genios), dotados, no se sabe por quién o por qué, de una capacidad superior de vivir o experimentar la realidad. Finalmente, el a priori es más institucional, por tanto histórico, de lo que parece. Pero esto, lo sublime y el genio y una sociología histórica de la educación artística, no es tema de este artículo. ${ }^{10}$ Volvamos al tema: ¿qué hace al texto de Ortega interesante, más allá de constatar sus raíces en la ideología literaria dominante desde el romanticismo?

\subsection{Final y conclusiones. In principio erat Jakobson}

Lo que presentamos en esta última sección puede parecer una simplificación brutal, pero únicamente pretendemos representar un mapa cognitivo del magma ideológico compartido por todas las escuelas de teoría, crítica e historia literaria en el turno de siglo, la matriz común que es producida ya por el paradigma kantiano a finales del siglo XVIII. En el siglo XX, con el formalismo ruso y las vanguardias, en lo que se refiere a los estudios literarios, tiene lugar una transformación decisiva a la que se adaptan los distintos campos culturales europeos en el período de entreguerras.

Ortega efectúa en España el trabajo de formulación teórica que los formalistas rusos y checos realizan en el resto de Europa, primero y, luego, en Estados Unidos. El concepto estético de Wellek y Warren (véase nota 5), su representación de la literatura, bebe de la construcción kantiana de especificidad y autonomía estética universalista, al implicar un "reino estético" específico -

10 La autonomía estética surge precisamente, cuando comienza la autonomización de los campos de producción cultural en el romanticismo, tras la pérdida de la hegemonía del canon aristocrático neoclásico (cf. Arnold Hauser); la ideología de un sujeto libre, creador, va paralela del mercado (cf. Juan Carlos Rodríguez, op.cit.), y este de la autonomización cultural (cf. Les règles de l’art: genèse et structure du champ littéraire (1992), título que es una cita-alusión, por cierto, de la Crítica del juicio (ver García Morente 1975: 195). Solamente lo apuntamos muy brevemente. 
las formas más o menos puras - en el interior de la obra. Las universidades americanas eran un campo, por otro lado, por razones ideológicas fácilmente relacionables a lo que hemos desarrollado aquí, preparado por el New Criticism. Fenomenología, neokantismo y psicologismo responden a un paradigma que comparte esas creencias en la autonomía, el sujeto creador y el universalismo estético, en tensión dialógica con el historicismo hegeliano o positivista. Obviamente la explosión de estudios humanísticos después de la Segunda Guerra Mundial diversificará increíblemente las corrientes teóricas y críticas.

El trabajo es el de la idea de la autonomización artística, paralela a la autonomización de los campos de producción cultural en la modernidad, la fabricación de una Norma literaria nueva en expresión de Juan Carlos Rodríguez -, de cuño ideológico subjetivo e idealista-neokantiano. Hoy es una ideología prácticamente global, porque el sistema capitalista es (usando expresión de I. Wallerstein), un "sistema-mundo".

La estilística española (Amado Alonso, Raimundo Lida, Dámaso Alonso) en la teoría, historia y crítica literaria hispánicas, junto al historicismo de Ramón Menéndez Pidal, vendrán a consolidar los caminos abiertos por la fenomenología, el psicologismo y el neokantismo introducidos en España de la mano de Ortega y Gasset.

En el terreno español, la deshumanización del arte se convertirá en un punto nodal en las redes creativas, interpelando profundamente a los escritores de vanguardia, porque precisamente se trata de una interpelación ideológica - la creencia en el sujeto - compartida. Cabe preguntarse, por último (y lo dejamos apuntado), por el conflicto ideológico, el porqué de la necesidad de producir y reproducir perseverantemente esta imagen de subjetivación creativa (paradójicamente) "universal".

El surrealismo querrá romper las barreras entre la vida y la poesía. La política y el neopopularismo lo complicarán todo, poco después, "las cosas se han ido gastando a fuerza de ser apuradas, de depuración" (García 2015: 233). Pero la creencia en la autonomía creativa es un pilar incuestionado. Luego llegará el fascismo, la guerra civil y la destrucción del campo cultural, y su reconstrucción en otro paradigma al que los agentes deberán adaptarse. Tras un periodo extraño de hegemonía realista, volverá el radicalismo de las formas en los sesenta en novela y el culturalismo poético de los ochenta. Pero el eje permanecerá, como norma. ${ }^{11}$ Hoy es - quizás - distinto porque, globalizada la ideología del sistema-mundo, como ya señalaba el filósofo norteamericano Fredric Jameson en su Postmodernism, or, The Cultural Logic of Late Capitalism (1991), la inmensa dilatación de la esfera de las mercancías ha venido acompañada de una aculturación de lo Real y una estetización de la realidad. Pero precisamente, por ello, y en plena crisis de las humanidades, regresa la cuestión de la autonomía creativa.

11 Sintomático es en 1990 (en ed. Anthropos) el título de una historia de la novela realizado por Pablo Gil Casado: La novela deshumanizada española (1958-1988), un estudio por otro lado excelente. 


\section{Referencias bibliográficas}

Blanco Aguinaga, C. (1997-1998). Sobre Estilística y Formalismo ruso. Cauce - revista de filología y su didáctica, 20-21, 29-44.

Bourdieu, P. (1992). Les Régles de l'art. Genèse et structure du champ littéraire. París: Seuil.

Černý, V. (2008). Ortegy y Gassetova teorie „umění odlidštěného“. In V. Černý, Š. Grauová (ed.), Studie o španělské literatuře, (pp. 273-280). Praga: Cherm. [Orig.: Host 8, 1929, č. 4, leden, str. 87-91.]

Forbelský, J. (2008). Václav Černý a hispanismus. In V. Černý (2008), pp. 389-399.

García, M. Á. (2015). La crítica de Antonio Marichalar y las vanguardias en España. De la creación pura al "Superromanticismo desollado". Études romanes de Brno, 36 (2), 223-236. <http://digilib.phil.muni.cz/ handle/11222.digilib/112967>

García Morente, M. (1975 [1917]). La filosofía de Kant (una introducción a la filosofía). Madrid: EspasaCalpe, Colecc. Austral.

Nieto Yusta, C. (2007-2008). José Ortega y Gasset y La deshumanización del arte. Espacio, tiempo y forma. Serie VII. Historia del arte, 20-21, 285-299. <http://dialnet.unirioja.es/servlet/articulo?codigo=3182085>

Orringer, N. (1979). Ortega y sus fuentes germánicas. Madrid: Gredos.

Ortega y Gasset, J. (1966 [1925]). La deshumanización del arte e Ideas sobre la novela. In Obras completas, Tomo III (1917-1928) (pp. 353-428). 6a ed. Madrid: Revista de Occidente.

Rodríguez, J. C. (1990). Teoría e historia de la producción ideológica. Madrid: Akal.

_. (1994 [1984]). La norma literaria. 2a ed. coor. aum. Granada: Diputación Provincial de Granada. [3a. ed. en Madrid, ed. Debate, 2001.]

. (2015). Para una teoría de la literatura (40 años de Historia). Madrid - Barcelona - Buenos Aires

- Sao Paulo: Marcial Pons. 


\section{Apéndice:}

Jaroslav Vrchlický (1853-1912) [Trad. Calderón]

František Xaver Šalda (1867-1937)

Karel Titz (1880-1940)

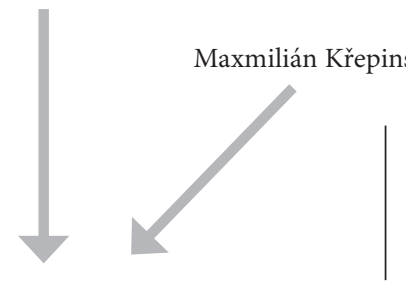

Pražský lingvistický kroužek (1926-

Vilém Mathesius (1882-1945)

Jan Mukařovský (1891-1975)

\section{Václav Černý (1905-1987)}

Bergson a ideologie současných romantiků (1928), doktorská práce

Ideové kořeny současného umění (1929)

Esej o básnickém baroku (1937)

Zdeněk Šmíd (1908-1989) [Trad. Quijote]

\section{Tercera generación de hispanistas:}

Josef Dubský (1917-1996)

OldřichTichý (1916-1991)

Oldřich Bělič (1920-1984)

Eduard Hodoušek (1921-2004) (Trad. Regenta, 1982, publ. 2002)

Kamil Uhlír (1923-1983)

\section{Ramón Menéndez Pidal}

(1869-1968) Menéndez Pidal se stal Černému prrímluvcem, aby byl v roce 1965 přijat za zahraničního člena Španělské královské akademie (Forbelský p. 395) 